\title{
Direct expansion ground source heat pump using carbon dioxide as refrigerant: Test facility and theoretical model presentation
}

\section{Parham Eslami Nejad Zine Aidoun}

\author{
Messaoud Badache
}

\author{
Mohamed Ouzzane
}

\begin{abstract}
In an attempt to address recent challenges on using natural refrigerants and to develop further knowledge and expertise in the field of direct expansion ground source heat pump (DX-GSHP), an experimental transcritical carbon dioxide $\left(\mathrm{CO}_{2}\right)$ test bench was built at CanmetENERGY Research Laboratory. A previously developed theoretical model of the system was modified and validated against a set of experimental results and adopted to investigate the system performance in a wide operating range. A parametric analysis was also performed using the theoretical model for understanding the system and at exploring the performance improvement actions for future installations. Validation results showed that the model predicts the experimentation very well within the uncertainty of the measurement. Furthermore, parametric analysis showed that improper control of some parameters such as gas cooler $\mathrm{CO}_{2}$ outlet temperature and discharge compressor pressure can degrade the system performance by up to $25 \%$ and the heat pump beating capacity by $7.5 \%$.
\end{abstract}

\section{NTRODUCTI ON}

Although the detrimental environmental impacts of conventional refrigerants have raised global concern, due to the worldwide growing energy demand, high energy efficiency of heat pumps still remains a great incentive for using this technology in residential and commercial buildings. Over the last decade, several studies have been conducted to replace synthetic refrigerants with natural ones. Among the candidates, $\mathrm{CO}_{2}$ has been attracting more attention as it is environmentally benign and safe. This, together with the established energy efficiency advantages of the GSHP, makes the $\mathrm{CO}_{2}$ GSHP a promising, environmentally friendly, and energy efficient alternative to other heating equipment. However, the scarcity of related technical knowledge may slow down its development pace.

Many studies have been performed on the air-source and water-source transcritical $\mathrm{CO}_{2}$ heat pump systems that are not the focus here; in general however, modeling of the DX-GSHP has been rarely studied (Ndiaye 2016). Kruse and Russmann (2005) and Bertsch et al. (2005) proposed a ground heat pipe technology with two-phase $\mathrm{CO}_{2}$ as a secondary fluid for extracting heat from the ground and transferring it to the GSHP using the thermosyphon principle. Both studies used pipe-in-pipe configurations. They compared the proposed system with a conventional system using a single phase water/brine solution.

Recently Mastrullo et al. (2014) performed modeling of a $\mathrm{CO}_{2}$-filled U-tube ground heat exchanger (borehole) under thermosyphon principle for the secondary loop GSHP systems. Another study by Eslami Nejad et al. (2014)

Parham Eslami Nejad (Parham.eslaminejad@canada.ca) is a research scientist at Natural Resources Canada, CanmetENERGY. Messaoud Badache, Mohamed Ouzzane and Zine Aidoun are research scientists at Natural Resources Canada. 
focused on the numerical modeling of $\mathrm{CO}_{2}$-filled U-tube vertical boreholes under forced circulation.

Very few works have looked at the whole $\mathrm{CO}_{2}$ GSHP cycle. Austin and Sumathy (2011) simulated a simple $\mathrm{CO}_{2}$ transcritical cycle. However, they did not account for dynamic characteristics of the system. A recent study by Eslami Nejad et al. (2015) developed a quasi-transient $\mathrm{CO}_{2}$ transcritical ground source heat pump model along with numerical and experimental validation of the borehole portion. In the present study, the model is validated using a set of experiments performed at CanmetENERGY Research Laboratory and then, it is modified and used to perform a parametric analysis on several system parameters.

\section{SYSTEM DESCRI PTION}

Figure 1 shows the schematic presentation of a single-stage transcritical $\mathrm{CO}_{2}$ DX-GSHP system with hot gas bypass working in heating mode. The system consists of eight main system components including compressor (1-2), gas cooler (2-3), internal heat exchanger (3-4), two different expansion valves (4-5 and 6-7), pressure regulating valve (9-10), receiver (5-6) and boreholes (7-8).

As shown in Figure 1, $\mathrm{CO}_{2}$ (Refrigerant) is flowing through a complete cycle by going directly down to the borehole, changing direction at the bottom (U connection) and coming up to extract heat (qb) from the ground by evaporation. Then it enters the internal heat exchanger (IHE) to exchange heat with the gas at the gas cooler exit in order to be superheated to a certain degree. The gas is then compressed by the compressor to supercritical pressure with a corresponding temperature rise. The high pressure/high temperature vapor enters the gas cooler to heat the water $\left(\mathrm{q}_{\mathrm{h}}\right)$. After the IHE, low temperature/high pressure $\mathrm{CO}_{2}$ gas is throttled to the intermediate pressure level of the cycle. Two-phase $\mathrm{CO}_{2}$ (vapor and liquid) enters the separator and the vapor part is bypassed around the boreholes. Both liquid and vapor parts are throttled to the low pressure level of the cycle. Finally, $\mathrm{CO}_{2}$ with very small vapour quality enters the boreholes and mixes with bypassed vapor at the borehole outlet.

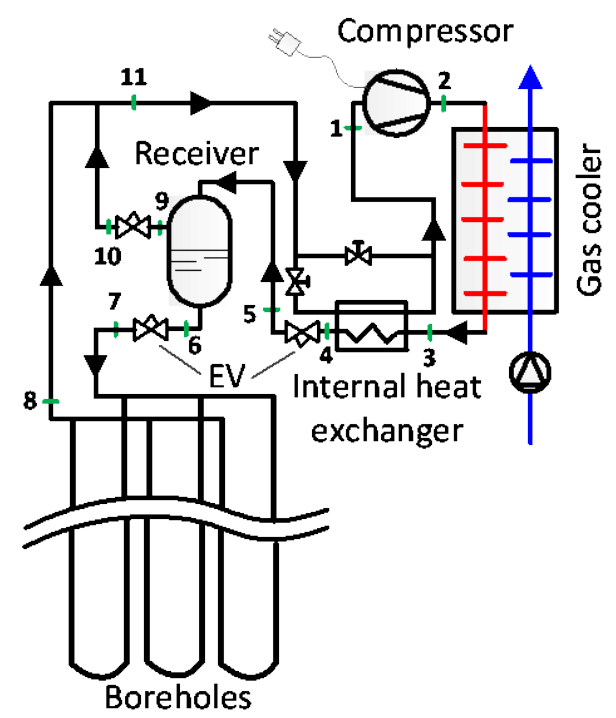

(a)

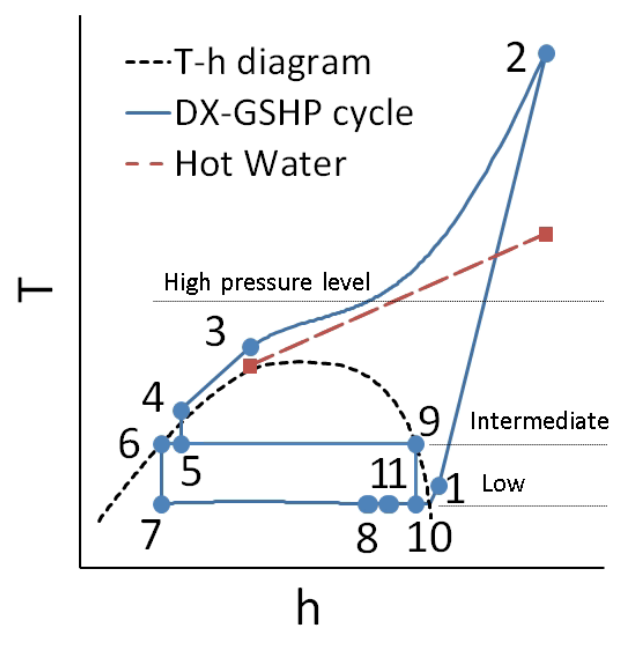

(b)

Figure 1 (a) System schematic and (b) qualitative temperature-enthalpy curve 


\section{THEORETI CAL MODEL}

The theoretical model comprises transient analytical model of the ground, steady-state numerical heat transfer models of the borehole and gas cooler, and steady-state heat transfer and thermodynamic models of other components such as the expansion valves, pressure regulating valve the compressor, the IHE and the receiver.

\section{Ground heat exchanger and the soil}

The numerical steady-state fluid flow and heat transfer model of the borehole developed by Eslami-Nejad et al. (2014) is adopted and combined with the transient classical finite line source (FLS) model of the ground. FLS is used for modeling the heat transfer in the the ground as well as the thermal interaction between boreholes with the heat pulse response superposition in time using a non-history scheme proposed by Lamarche and Beauchamp (2007). For validation of the ground-heat exchanger model, readers are referred to Eslami-Nejad et al. (2015). It is assumed that the grout and ground materials are homogeneous and the heat capacity of the grout is negligible.

\section{Gas cooler}

Counter-flow heat exchanger is assumed for the gas cooler. The gas cooler is also discretized along its length into equal control volumes to account for strong temperature-heat-transfer-rate nonlinear behavior in the supercritical region (Chen 2016). Calculation starts from the outlet of the $\mathrm{CO}_{2}$ side and the inlet of the water side where both temperatures are known. In addition to energy balance between water and $\mathrm{CO}_{2}$, the LMTD method is used to calculate heat exchange rate at each control volume. Fundamental conservation equation of momentum based on appropriate correlations for $\mathrm{CO}_{2}$ pressure drop is also applied to each control volume element. The system of equations obtained (energy, heat transfer and momentum) is nonlinear and strongly linked. An iterative method is therefore applied to solve the set of equations (Eslami-Nejad et al. 2015).

\section{Compressor}

The volumetric and isentropic efficiency equations, Eq. 1 and Eq. 2 respectively, have been correlated using manufacturer data and used along with other equations to calculate $\mathrm{CO}_{2}$ total mass flow, compressor work, discharge pressure and temperature.

$$
\begin{gathered}
\eta_{v}=1.0649-0.1044\left(\frac{P_{2}}{P_{1}}\right) \\
\eta_{\text {isen }}=0.518+0.0666\left(\frac{P_{2}}{P_{1}}\right)-0.0137\left(\frac{P_{2}}{P_{1}}\right)^{2}
\end{gathered}
$$

Fundamental energy, mass or thermodynamic equations are used for other system components (expansion valves, IHE and separator) to complete the system of equations (Eslami-Nejad et al. 2015).

\section{Solution procedure}

At each time step, three main iterative numerical procedures, as well as several internal iterative calculation loops, are used to determine the operating conditions of the system components as well as the ground thermal condition for the next time step. In the last iterative loop, the borehole wall temperature is updated, using the transient heat transfer calculation in the ground. Based on the convergence criteria for each loop, all three main loops 
interact iteratively until they all converge. The code is developed in FORTRAN, to which REFPROP Version 9.1 subroutines (Lemmon et al. 2013) are linked, to calculate the thermodynamic properties of $\mathrm{CO}_{2}$ and water. More details about different components have been described in Eslami Nejad et al. (2015)

\section{EXPERI MENTAL TEST BENCH}

In an attempt to address recent challenges on using natural refrigerant in heat pumps and to develop more expertise on $\mathrm{CO}_{2}$ DX-GSHP, an experimental test bench was built at CanmetENERGY Research Laboratory. The test facility is a transcritical $\mathrm{CO}_{2}$ DX-GSHP with a hot gas bypass working in heating mode. It comprises a semi hermetic compressor (Table 1), a water loop for heat rejection from the gas cooler, two counter-flow plate heat exchangers for the gas cooler $\left(A_{G C}=0.74 \mathrm{~m}^{2}\right.$ and $\left.U A_{G C}=0.3 \mathrm{~kW} / \mathrm{K}\right)$ and for IHE $\left(A_{I H E}=0.092 \mathrm{~m}^{2}\right.$ and $\left.U A_{I H E}=0.1 \mathrm{~kW} / \mathrm{K}\right)$, as well as four 30 -meter vertical boreholes with single copper $\mathrm{U}$-tube. The boreholes are arranged in a square pattern with a uniform spacing of $6.25 \mathrm{~m}$. Borehole dimensions are listed in Table 2. Insitu thermal properties of the soil obtained from a thermal response test are given in Table 3.

Table 1. Compressor

\begin{tabular}{|c|c|c|c|}
\hline \multirow{3}{*}{ 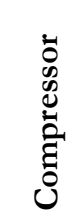 } & Nominal refrigeration capacity & ton & 1 \\
\hline & Nominal power input & $\mathrm{kW}$ & 1.36 \\
\hline & Compressor speed & $\mathrm{m}^{3} / \mathrm{h}$ & 1.12 \\
\hline
\end{tabular}

Table 3. Ground thermal properties

\begin{tabular}{c|lcc}
\hline \multirow{5}{*}{} & $K_{\text {ground }}$ & $\mathrm{W} / \mathrm{m} / \mathrm{K}$ & 2.65 \\
& $\left(\rho c_{p}\right)_{g}$ & $\mathrm{~kJ} / \mathrm{m}^{3} / \mathrm{K}$ & 2862 \\
& $T_{\text {ground }}$ & ${ }^{\circ} \mathrm{C}$ & 9.0 \\
\hline
\end{tabular}

Table 2. Borehole dimensions

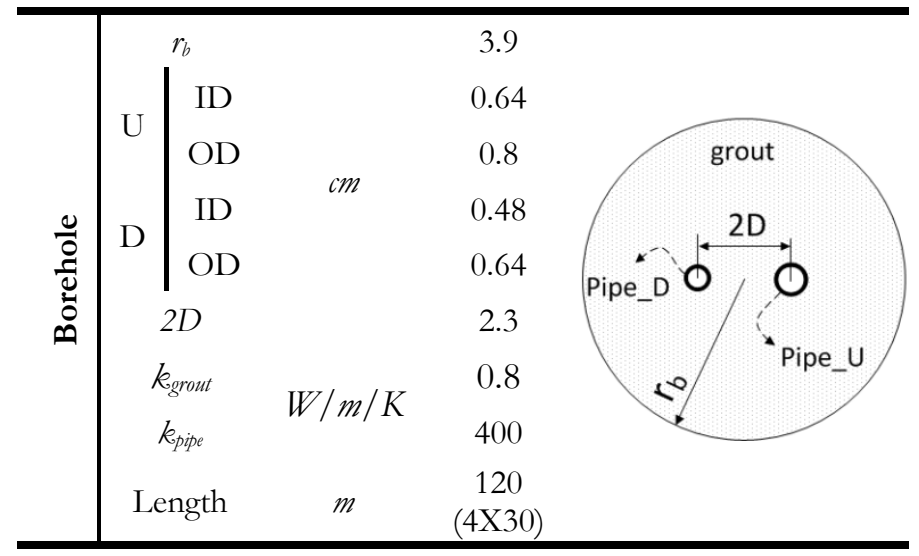

The setup is fully equipped with different measuring devices including an electric power meter, pressure and temperature sensors and flow meters to evaluate precisely the overall system performance as well as every specific components of the cycle. Figure $2 \mathrm{a}$ presents a schematic of the test bench with all measuring devices at different locations.

The cycle is divided into three pressure zones (Figure 2a): high (red dash line), intermediate (orange long dash line) and low (blue solid line) pressure. The solid orange line in Figure 2a shows the oil flow path from the oil separator to the compressor. The oil mixes with $\mathrm{CO}_{2}$ and therefore it leaves the compressor to the oil separator. System heat transfer losses to the ambient is minimised through sufficient insulation. Figure $2 \mathrm{~b}$ is the picture of the test bench located in CanmetENERGY laboratory.

The system can be operated in two different modes; automatic and manual. The automatic mode is focused on this paper and it is described in the following section. In the manual mode the opening position of the expansion valves installed before the boreholes can be changed manually.

\section{Control}

In automatic mode, four control strategies are applied as follows:

- The valve that discharges the vapor from the receiver maintains the intermediate pressure $\left(P_{\text {receiver }}\right)$ at $3750 \mathrm{kPa}$. This value is the set point given by the operator that corresponds to $\mathrm{CO}_{2}$ saturation temperature of $2.8^{\circ} \mathrm{C}$. 

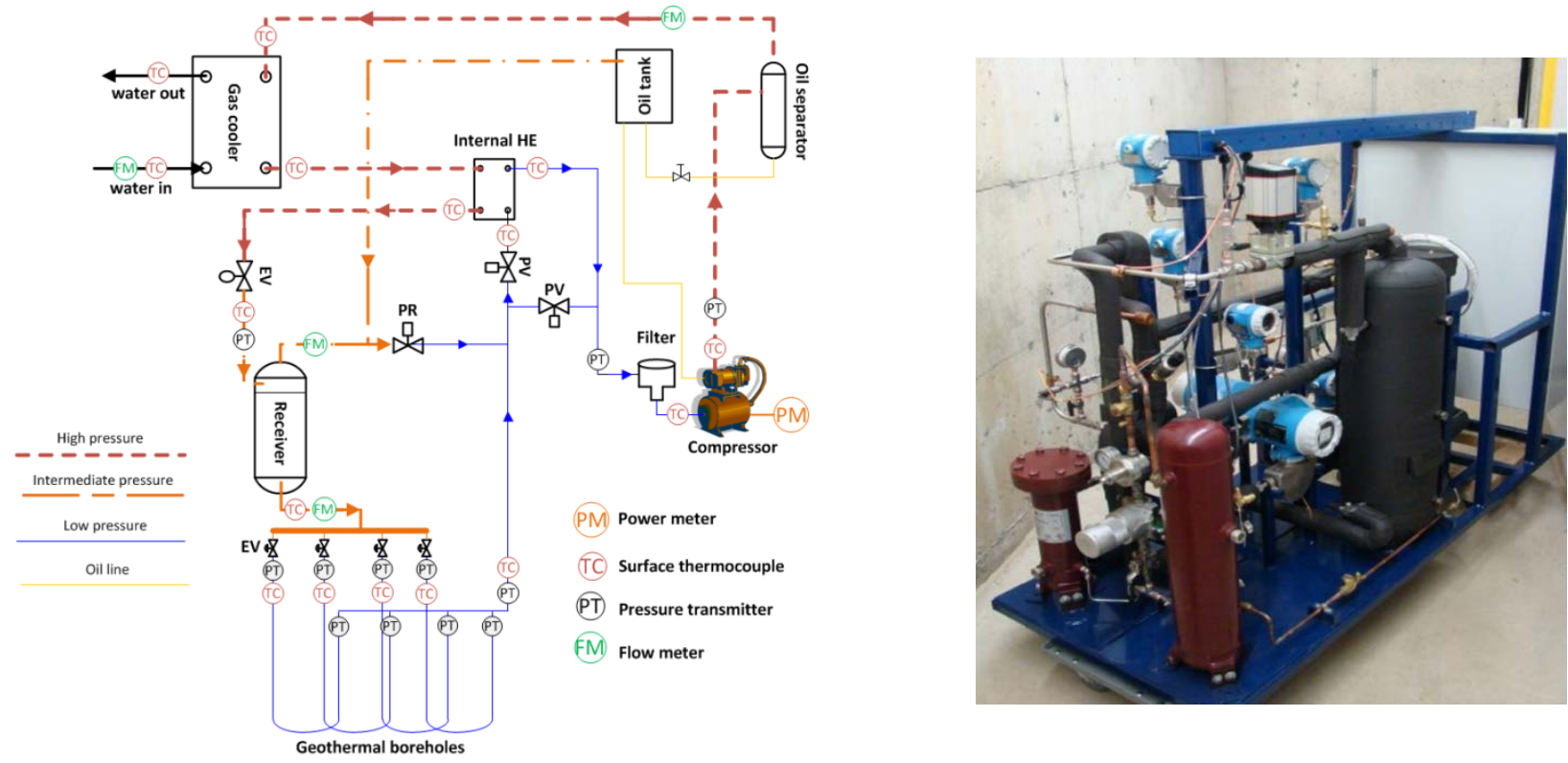

Figure 2 (a) System schematic of the test bench (b)Test bench at CanmetENERGY

- Optimum high pressure is controled by the expansion valve installed after the IHE on the high pressure level. Several tests were performed to correlate the following control fuction giving the optimum pressure $\left(P_{o p t}\right)$ in $\mathrm{kPa}$ as a function of gas cooler outlet temperature $\left(T_{g, c o u t}\right)$ in ${ }^{\circ} \mathrm{C}$.

$$
\mathrm{P}_{\mathrm{opt}}\left(\mathrm{T}_{\mathrm{gc}, \mathrm{CO} 2}\right)=149.7 \times \mathrm{T}_{\mathrm{gc}, \mathrm{out}}+2588.4
$$

- Expansion valves' opening changes automatically to be able to provide superheat temperature set point $\left(1.5^{\circ} \mathrm{C}\right)$ at the borehole exit.

- Two valves installed at the low pressure level before the IHE satisfy the second superheat set point $\left(5.0^{\circ} \mathrm{C}\right)$ at the compressor suction by modulating the flow of $\mathrm{CO}_{2}$ passing through the IHX.

\section{Measurements and uncertainty}

Uncertainties of measuring equipments are presented in Table 4. The uncertainty of temperature measurement can go upto $\mathbf{\pm} 0.8^{\circ} \mathrm{C}$ (for measuring high temperatures) due to the use of pipe surface thermocouples. Temperature uncertainties due to heat losses from pipe surface to the ambient and the thermal contact resistance between the thermocouples and the pipe surface is not taken into account.

\section{Table 4. Measurement uncertainties}

\begin{tabular}{lll}
\hline Measured parameters & Equipment & Uncertainty \\
\hline Temperature & T-type thermocouples & $\pm 0.5{ }^{\circ} \mathrm{C}$ \\
$\mathrm{CO}_{2}$ mass flow rate & Coriolis flowmeter & $\pm 0.2 \%$ \\
Water mass flow rate & Magnetic flowmeter & $\pm 0.5 \%$ \\
Pressure & Transducers & $\pm 0.6 \%$ \\
Power input to the compressor & Wattmeter & $\pm 0.2 \%$ \\
\hline
\end{tabular}




\section{VALI DATI ON}

There are minor differences between the theoretical model (based on Figure 1a) and the installation (Figure 2a), including separate expansion valve for each borehole and an oil circuit in the test bench but neither of which was considered by the model. A 17-hour experiment was performed in heating mode for model validation with constant water mass flow rate $\left(\dot{\boldsymbol{m}}_{\boldsymbol{w a t e r}}\right)$ entering the gas cooler at $0.25 \mathrm{~kg} / \mathrm{s}$ and constant inlet water temperature at $35^{\circ} \mathrm{C}$. As shown in Figure 3, $\mathrm{CO}_{2}$ pressure value reaches $8300 \mathrm{kPa}$ at the gas cooler inlet. Furthermore, intermediate pressure $\left(P_{\text {receiver }}=3750 \mathrm{kPa}\right)$ is very close to the low pressure $\left(P_{\text {in_borebole }}=3540 \mathrm{kPa}\right)$ level. Evaporating pressure $\left(P_{\text {in_borebole }}\right)$ decreases slightly over time from $3540 \mathrm{kPa}$ to $3412 \mathrm{kPa}$; this is caused by the expansion valves to maintain the superheat set point at the borehole outlet. Water temperature increases by $3.5^{\circ} \mathrm{C}$ (from $35^{\circ} \mathrm{C}$ to $38.5{ }^{\circ} \mathrm{C}$ ) taking the heat from $\mathrm{CO}_{2}$ in the gas cooler $\left(q_{b}\right)$ and corresponding to nearly 3.6 kilowatts of heating.

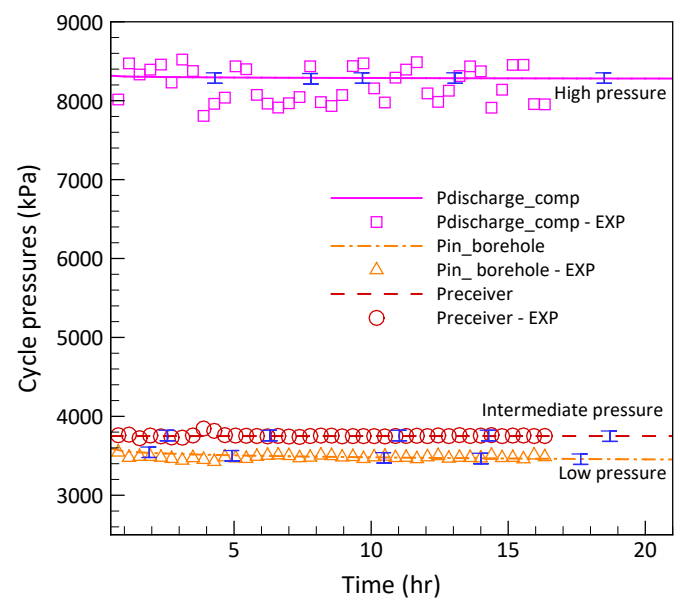

Figure 3 Cycle pressure levels

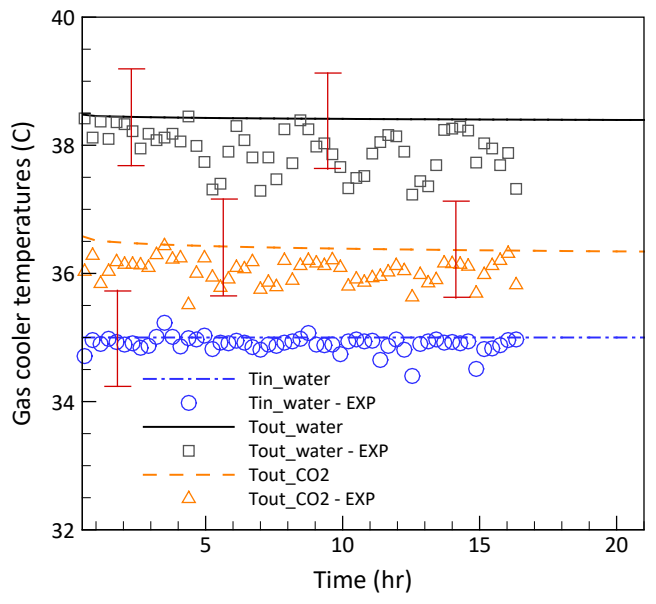

Figure 4 Gas cooler temperatures

The model was modified to include the four control strategies implemented into the test bench. Figures 3 and 4 present predicted (line) and measured (symbols) pressure levels of the heat pump and gas cooler water and $\mathrm{CO}_{2}$ temperatures. The model shows a very good agreement with experimental data considering the measurement uncertainties (Error bars); except, discharge pressure that fluctuations beyond uncertainties mainly due to the superheat control strategy (last point of the control subsection).

\section{PARAMETRI C ANALYSIS}

For a better understanding of the system and at exploring the performance improvement actions, a parametric analysis was undertaken using the theoretical model. This analysis focuses on producing domestic hot water using the DX $\mathrm{CO}_{2}$ GSHP. Eight different cases are considered and compared against the base case. The ninth case is also considered combining the best two individual cases $(\# 5 \& \# 1)$. All system parameters of the base case which are different from that of the test bench are presented in Table 5. One parameter at a time is changed in each case (\#1 to $\# 8$ ) to evaluate the effect of six different parameters including the degree of superheat at the compressor suction $\left(\Delta T_{s_{-} \text {comp }}\right)$, inlet water temperature to the gas cooler $\left(T_{\text {in_water }}\right), \mathrm{CO}_{2}$ gas cooler outlet temperature $\left(T_{\text {out_CO2}}\right)$, intermediate pressure $\left(\mathrm{P}_{\text {receiver }}\right)$, water mass flow rate $\left(\dot{\mathbf{m}}_{\text {water }}\right)$ and IHE efficiency $\left(\varepsilon_{\mathrm{IHE}}\right)$. The optimum pressure 
control is not adopted here for the parametric analysis as the $\mathrm{CO}_{2}$ outlet temperature from the gas cooler is kept constant. Superheat controls at the borehole outlet and at the compressor suction are combined here into one control at the compressor suction and the entire $\mathrm{CO}_{2}$ flow is going through the IHE. The overal heat transfer coefficient $(U)$ of the gas cooler varies from case to case and with evaporating temperature due to changes in $\mathrm{CO}_{2}$ mass flow rate and properties $\left(U A_{G C}\right.$ changes from 0.12 to $\left.0.3 \mathrm{~kW} / \mathrm{K}\right)$.

Table 5. Different cases for parametric analysis

\begin{tabular}{|c|c|c|c|c|c|c|}
\hline \multicolumn{4}{|c|}{ Base Case } & \multicolumn{3}{|c|}{ Other cases } \\
\hline \multirow{4}{*}{$\begin{array}{l}\stackrel{0}{0} \\
\frac{0}{0} \\
\stackrel{0}{0} \\
0\end{array}$} & ID & \multirow[b]{2}{*}{$\mathrm{cm}$} & 0.64 & $\# 1$ & $T_{\text {out_CO2 }}$ & $25^{\circ} \mathrm{C}$ \\
\hline & OD & & 0.8 & $\# 2$ & $T_{\text {in_wwater }}$ & $25^{\circ} \mathrm{C}$ \\
\hline & $k_{\text {grout }}$ & $W / m / K$ & 1.0 & $\# 3$ & $\Delta T_{s_{1} \text { comp }}$ & $10{ }^{\circ} \mathrm{C}$ \\
\hline & Length & $m$ & $3 \times 30$ & $\# 4$ & $\Delta T_{\text {sh_comp }}$ & $1{ }^{\circ} \mathrm{C}$ \\
\hline \multirow{4}{*}{$\mathbb{S}^{\infty} \frac{\dot{t}}{0}$} & $T_{\text {ground }}$ & ${ }^{\circ} \mathrm{C}$ & 9.0 & \#5 & $\dot{m}_{\text {water }}$ & $0.03 \mathrm{~kg} / \mathrm{s}$ \\
\hline & $\dot{m}_{\text {water }}$ & $\mathrm{kg} / \mathrm{s}$ & 0.025 & \#6 & $\dot{m}_{\text {water }}$ & $0.02 \mathrm{~kg} / \mathrm{s}$ \\
\hline & $T_{\text {in_water }}$ & ${ }^{\circ} \mathrm{C}$ & 20 & \#7 & $P_{\text {receiver }}$ & $3578 \mathrm{kPa}$ \\
\hline & $T_{\text {out } C \mathrm{CO} 2}$ & ${ }^{\circ} \mathrm{C}$ & 30 & $\# 8$ & $\varepsilon_{I H E}$ & $10 \%$ \\
\hline \multirow{3}{*}{$\frac{\dot{\Xi}}{0}$} & $\Delta T_{\text {sh_comp }}$ & ${ }^{\circ} \mathrm{C}$ & 5.0 & & & \\
\hline & $P_{\text {receiver }}$ & $\mathrm{kPa}$ & 4500 & $\# 0$ & $\dot{m}_{\text {water }}$ & $0.03 \mathrm{~kg} / \mathrm{s}$ \\
\hline & $\varepsilon_{I H E}$ & & $40 \%$ & +7 & $T_{\text {out_CO2 }}$ & $25^{\circ} \mathrm{C}$ \\
\hline
\end{tabular}

Figures 5, 6, 7 and 8 summarize the parametric analysis by demonstrating the effects of several parameters on $\mathrm{COP}$, gas cooler heating capacity, compressor work and discharge pressure over the mean evaporating temperature, respectively.

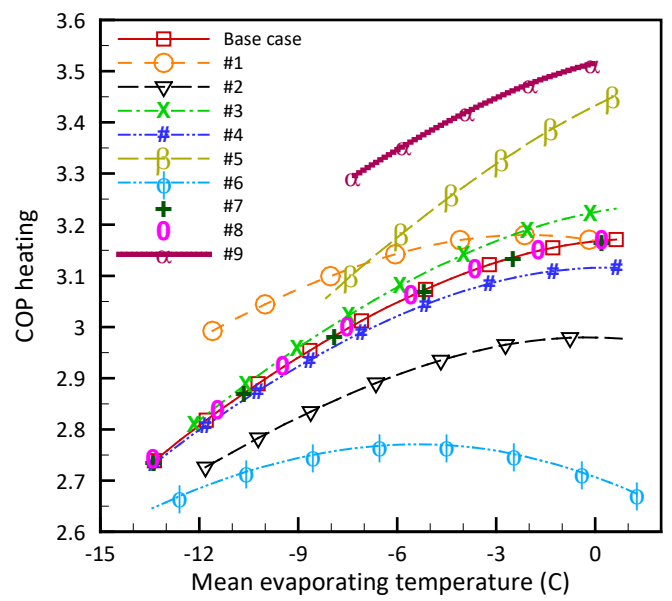

Figure 5 Coefficient of performance $\left(C O P_{\text {beating }}\right)$

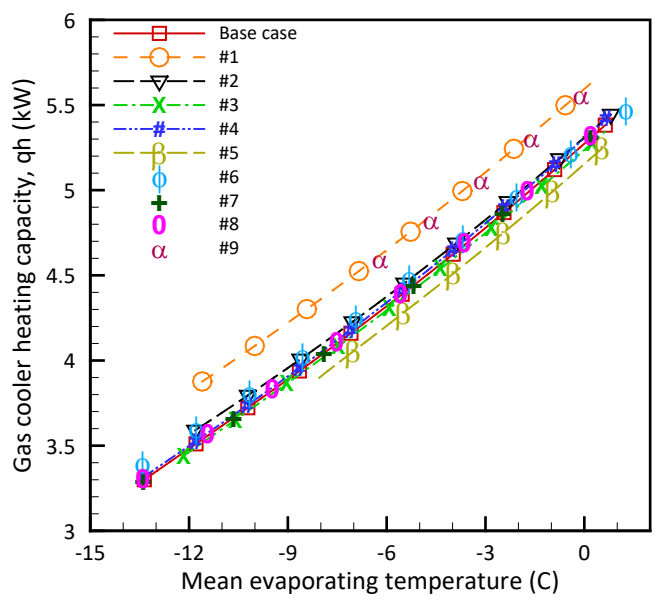

Figure 6 Gas cooler heating capacity $\left(q_{b}\right)$

As shown in Figure 5 , case \#5 $\left(\dot{\mathbf{m}}_{\text {water }}=0.03 \mathrm{~kg} / \mathrm{s}\right)$ offers the highest COP among cases \#1 to \#8 for evaporating temperatures from $-6{ }^{\circ} \mathrm{C}$ to $0{ }^{\circ} \mathrm{C}$ (up to $8 \%$ at $0{ }^{\circ} \mathrm{C}$ ). This is due to the fact that the discharge pressure is 
significantly lower (Figure 8) and thus the compressor work (Figure 7). However, Case \#5 demonstrates slightly lower gas cooler heating capacity compared to the base case.

Lowering the gas cooler outlet temperature (case \#1) also presents a positive effect on COP, particularly at low evaporating temperature (up to $6 \%$ at $-12{ }^{\circ} \mathrm{C}$ ). The gas cooler heating capacity also improves despite the increase in the discharge pressure (Figure 8) and compressor work (Figure 7). This is mainly due to the superior gas cooler performance at specific pressure and temperature conditions. On the contrary, by increasing the water temperature entering the gas cooler the COP reduces by up to $6 \%$ mainly due to the increase in the discharge pressure. Changing the IHE size and the intermediate pressure (\#8 and \#7 respectively) does not change the COP and $q_{b}$. Under given conditions, more superheat at the compressor suction improves marginally the COP, while less superheat (\#4) decreases slightly the COP. Lowering the water mass flow rate in \#6 decreases significantly the COP by $15 \%$ at $0{ }^{\circ} \mathrm{C}$. In order to satisfy the given $T_{\text {out_CO2 }}$ in \#6, discharge pressure increases (Figure 8) and ultimately does the compressor work (Figure 7).

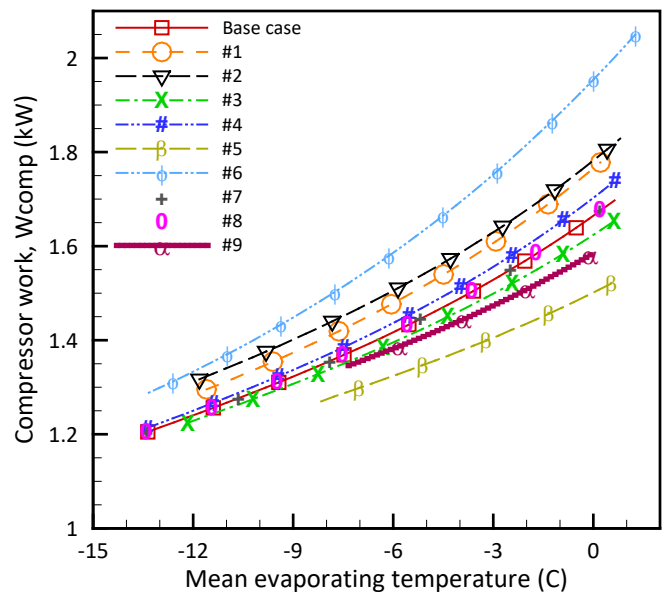

Figure 7 Compressor work $\left(W_{\text {comp }}\right)$

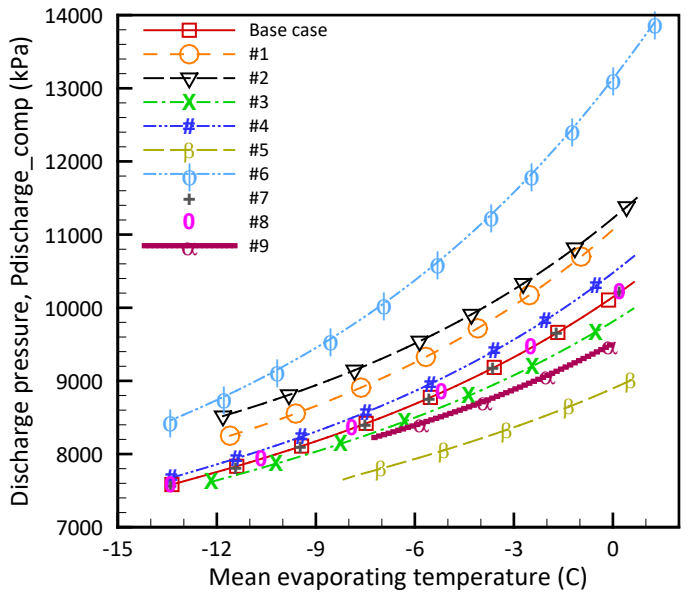

Figure 8 Discharge pressure $\left(P_{\text {discharge_comp }}\right)$

A combination of \#5 and \#1 (best cases) is also presented (\#9) at the end of this study to show how proper design and control can promote a good system performance. In this case $T_{\text {out } \_ \text {CO2 }}$ and $\dot{\mathrm{m}}_{\text {water }}$ are changed compared to the base case (Table 5). Results show a COP improvement by up to $25 \%$ compared to \#6 and 10\% compared to the base case. Gas cooler capacity is also improved by $7.5 \%$ compared to the base case

\section{CONCLUSION}

In this study, an experimental test bench of a transcritical $\mathrm{CO}_{2}$ DX-GSHP that was built at CanmetENERGY research laboratory was described. Then, a previously developed theoretical model of the system is modified and validated against a set of experimental results. Finally, a parametric analysis was performed using the theoretical model for understanding the system and at exploring the performance improvement actions.

Under using identical components and given conditions, the effect of various operating parameters on COP, gas cooler heating capacity, compressor work and discharge pressure was investigated. Results showed that improper control of some parameters such as gas cooler $\mathrm{CO}_{2}$ outlet temperature and discharge compressor pressure can 
degrade the system performance by up to $25 \%$ for hot water production application. Furthermore, right gas cooler selection for given water mass flow rate is very critical to get the best performance and maximum heat capacity.

\section{ACKNOWLEDGMENTS}

This work was financially supported by the Energy Innovation Program (Natural Resources Canada).

\section{REFERENCES}

Ndiaye, D. 2016. Reliability and performance of direct-expansion ground-coupled heat pump systems: Issues and possible solutions. Renewable and sustainable energy reviews 66: 802-814.

Kruse, H., and H. Russmann. 2005. Novel $\mathrm{CO}_{2}$-heat pipe as earth probe for heat pumps without auxiliary pumping energy. $8^{\text {th }} \mathrm{IH} A$ heat pump conference, Las Vegas, Nevada, USA.

Bertsch, S., E.A. Groll, and K. Whitacre. 2005. Modeling of a $\mathrm{CO}_{2}$ thermosyphon for a ground source heat pump application. $8^{\text {th }} \mathrm{IH} A$ heat pump conference, Las Vegas, Nevada, USA.

Mastrullo, R., A.W. Mauro, L. Menna, and G.P. Vanoli. 2014. A model for a borehole beat exchanger working with $\mathrm{CO}_{2}$. Energy Procedia 45: 635-644.

Eslami-Nejad, P., M. Ouzzane, and A. Aidoun. 2014. Modeling of a two-phase $\mathrm{CO}_{2}$-filled vertical borehole for geothermal heat pump applications. Applied Energy 114: 611-620.

Austin, B.T., K. Sumathy. 2011. Parametric study on the performance of a direct-expansion geothermal heat pump using carbon dioxide. Applied Thermal Engineering 31: 3774-3782.

Eslami-Nejad, P., M. Ouzzane, and A. Aidoun. 2015. A Quasi-transient Model of a Transcritical Carbon Dioxide Direct-Expansion Ground Source Heat Pump for Space and Water Heating. Applied Thermal Engineering 91: 259-269.

Lamarche, L. and B. Beauchamp. 2007. A new contribution to the finite line-source model for geothermal boreholes. Energy and Buildings 39: 188-198.

Chen Y.G. 2016. Pinch point analysis and design considerations of $\mathrm{CO}_{2}$ gas cooler for heat pump water heaters. International Journal of Refrigeration 69: 136-146.

Lemmon, EW., ML. Huber, and MO. McLinden. 2013. NIST Standard Reference Database 23: Reference Fluid Thermodynamic and Transport Properties-REFPROP, Version 9.1, National Institute of Standards and Technology, Standard Reference Data Program, Gaithersburg. 